\title{
Earth, Technology, Language: A Contribution to Holistic and Transcendental Revisions After the Artifactual Turn
}

\author{
Mark Coeckelbergh ${ }^{1}$ \\ Published online: 11 April 2021 \\ (C) The Author(s) 2021
}

\begin{abstract}
The empirical turn, understood as a turn to the artifact in the work of Ihde, has been a fruitful one, which has rightly abandoned what Serres and Latour call "the empire of signs" of the postmoderns. However, this has unfortunately implied too little attention for language and its relation to technology. The same can be said about the social dimension of technology use, which is largely neglected in postphenomenology. This talk critically responds to Ihde (mainly) and Stiegler, and sketches a Wittgensteinian inroad to a more holistic and transcendental revision of postphenomenology which does not turn away from the artifact but places it in a wider social context and asks the question regarding the relation between language and technology. Finally, since the earth may be the ultimate condition of possibility, it is asked what this language-sensitive and transcendental approach may imply for rethinking our human position and agency in the Anthropocene. The paper ends with pointing to the role of language as transcendental condition that shapes the very project of thinking the "Anthropocene."
\end{abstract}

Keywords Philosophy of technology $\cdot$ Language $\cdot$ Ihde $\cdot$ Postphenomenology Wittgenstein $\cdot$ Heidegger $\cdot$ Anthropocene $\cdot$ Earth

\section{Introduction}

The empirical turn in philosophy of technology (Achterhuis 2001), understood as a turn to the artifact in the work of Ihde, has been a necessary and fruitful one, which has rightly abandoned what Serres and Latour, perhaps referring to Roland Barthes's book, call "the empire of signs" of the postmoderns (Serres and Latour 1995, 132; Latour 1993, 64). However, as I argue in Using Words and Things and related work this has unfortunately implied too little attention for language and its relation to technology within much contemporary philosophy of technology (Coeckelbergh 2015, 2017, 2018). Moreover, the empirical turn for instance in Ihde has unduly, unfairly, and unnecessarily rejected the notion of the transcendental (Smith 2015; Zwier et al. 2016; Coeckelbergh 2017). Stiegler, on the other hand, sees technology also as milieu (Stiegler 2017) and talks about processes of grammatization

Mark Coeckelbergh

mark.coeckelbergh@univie.ac.at

1 Department of Philosophy, University of Vienna, Vienna, Austria 
(see also Tinnell 2015), which can be interpreted as a transcendental ground that constitutes both humans and technology. But it is unclear how his notion of technology as extension or organon connects to this and has room for thinking about language.

This paper critically responds to Ihde and, to a small extent, to Stiegler. It sketches a Wittgensteinian (1953) inroad to a more holistic and transcendental revision of postphenomenology which does not turn away from the artifact but places it in a wider social context and asks the question regarding the relation between language and technology. This approach, which starts from use rather than seeing technology as object or extension (but does not end with use), is very critical of empirical turn work. In particular, I propose some revisions to Ihde's postphenomenological framework of human-technology relations (Ihde 1990) and mediation theory (Verbeek 2005) that highlight the role of language and the way technology use is embedded in a social context. Finally, suggesting that the earth may be the ultimate condition of possibility, I end by asking what this language-sensitive and transcendental approach may imply for rethinking our human position and agency in the Anthropocene. I briefly respond to Stiegler's article which argues for going beyond the Anthropocene (Stiegler 2017) and I emphasize the role of language as transcendental condition that shapes the very project of thinking the "Anthropocene."

\section{Using Wittgenstein for Thinking About Technology}

As I have argued previously (Coeckelbergh 2017, 2018), the later Wittgenstein can be used in philosophy of technology by adopting his approach to language and then applying this to technology. Let me outline my proposal and the implications for (Ihde's) postphenomenology_bringing together different strands of previous work and clarifying its implications in ways that could be helpful to postphenomenology scholars and others in philosophy of technology. In particular, I will stress the role of language and highlight the social dimension of technology use.

Wittgenstein's view of language is, firstly, use-centered: he argues that the meaning of words depend on their use. He compares them with tools in a toolbox (Wittgenstein 1953, 9e). Secondly, it is holistic. Wittgenstein argues that the use of language is woven into activities and what he calls language-games: 'I shall also call the whole, consisting of language and the activities into which it is woven, a "language-game" (Wittgenstein 1953, $9 \mathrm{e})$. Another term he uses is 'form of life' (11e). The point is that language is not a separate realm of signs but is part of what we do and how we do things in a particular social context. One could call it a "culture," but the danger of such a term is that it can be seen as a separate thing or realm; instead, it is always a matter of activities, including engagements with technology. To further specify the relation between use and form of life, thirdly, we can add a transcendental interpretation: not transcendent, since the whole does not have any existence next to or above use, but transcendental in the sense of conditions of possibility: a concrete use is made possible by a context of games and form of life that gives meaning to the particular use. This interpretation is in line with Gier (1980), who interpreted forms of life as patterns in our lives that 'make a meaningful world possible' (Gier 1980, 257). I have also used a language metaphor to say this: it is a kind of grammar, not just a syntax (how to put words together) but also how and when to use the words in the right context. When you learn a new language, for example, first you have to learn the words and the syntax. But if you really want to reach an advanced level, you have to know how and when to use the words in relation to the relevant activities and social games. 
I have proposed to use this view of language for thinking about technology. Language use is not only like technology use, as Wittgenstein claimed when he used his toolbox metaphor; we can turn the metaphor around and argue that technology use is also a lot like language use, at least if we understand language in a Wittgensteinian way. First, the meaning of technologies, in so far as we consider them as tools and artifacts, lies in their use. Without that they are meaningless objects. Second, this use is always embedded in activities, games, and ultimately a form of life. Making sense of artifacts by putting them in a wider form of life, as anthropologists of distant cultures might do, is not just something that should be done for non-Western or "indigenous" cultures; it is just as much a good method for Western technologies. Our use of technologies, in so far as they are tools, must be understood within what we do and how we do it in a social context. On the one hand, the use of technologies co-constitute our activities, games, and form of life, which do not have an existence apart from our technological practices. On the other hand, particular uses of technology are made possible by these games and form of life, which structure and constrain these uses and the related meanings. This approach is also in line with Winner, who argued that technologies are part of a form of life since they are 'woven into the texture of everyday existence' (Winner 1986, 12).

\section{Revising and Moving Beyond Postphenomenology}

What does this Wittgensteinian approach imply for postphenomenology? Postphenomenology shares an interest in use. Ihde argued that a technological object becomes what it is through its uses (Ihde 1990, 70) and hence that the meaning of technology is multistable in the sense that it depends on the context (144). This is in line with what I have just said. But based on the Wittgensteinian approached sketched here, we can now add that in practice - that is, in concrete uses in a social context - there is not endless variability of use. In practice, the variability of use and meaning are limited by the transcendental conditions: the games and form of life. For example, we can use a knife for cutting but also for killing. But, say, an alien culture might have a totally different use for the same object and attach very different meanings to it, based on their culture-uses and meanings that cannot be imagined from within our culture. If the knife makes sense at all within that other, very alien culture. The range of meanings is thus always constrained by the form of life.

But what about further implications of the holism and the transcendental interpretation? There are at least two ways to revise postphenomenology in the light of these insights (Coeckelbergh 2017). One is to stay at the level of what Wittgenstein says about language and add language to the framework of human-technology relations, in particular as a mediator (next to technology). Here language is not seen as a separate realm of signs, but as interwoven with our material engagements. This intervention accounts for the mediating role of language, but does not take into account the further developments in a holistic and transcendental direction proposed here. Another is to re-think the relations framework itself, based on my application of Wittgenstein's view of language to technology. Let me sketch both options.

First, postphenomenology could learn from Wittgenstein, and from 20th-century philosophy of language more broadly, that next to the use of artifacts, the use of language is also an important kind of use that should not be neglected. In particular, it could learn that, just like technology, language also has unintended effects. Like technology, it is not just a neutral tool but shapes what we do and how we do it. Using postphenomenological language, 
one could say that language also plays a mediating role: as a kind of milieu and as a kind of in-between that shapes our relation to the world, to others, and indeed to technology.

Based on this insight, one could revise the postphenomenological framework in a way that accounts for the mediating roles of language. Language can mediate between humans and their world in various ways, and it can also play various mediating roles in relation to technology and how technology mediates (Coeckelbergh 2017, 170-175). Let me give a few examples. First, not only technological artifacts can be embodied; language is often embodied too. As we use language in an everyday context, it usually remains invisible. It is part of us. We do not think about it. Yet it shapes and structures our lives. Language can also mediate in a hermeneutic relation in at least two ways. First, it can be experienced as part of the world. For example, it can appear as text. We experience language then as a kind of "thing" that is part of the world. But just as a thermometer mediates our experience of warm and cold, language as text is also a mediator. It lets appear the world in a particular, non-neutral way. In both cases, we are not aware of its mediating role. Second, language can also mediate our engagements with technology (experienced as part of the world in the hermeneutic relation, it is not embodied or is not an alterity). How we experience technology (as part of our world) is then mediated by language. When we speak about a particular technology, language is hermeneutically active. It shapes how we speak and think about technology. What a particular technology "is" cannot be defined independently from our language use: how we name the technology, the narratives we tell about the technology, etc. will define what the technology "is" for us. For example, what "artificial intelligence" is, depends (among other things) on what various people say it is, on the language used to describe the technology, interact with it, and so on. Third, if we have an alterity relation with technology, for instance when technology appears to us in the form of a social robot, our interaction with that technology is mediated by language, which helps to make sense of the technology and the interaction. It is not a neutral tool, but-together of course with the material artifact-co-shapes the meaning and form of the interaction. For example, it matters if we use personal names for a robot or not. In mediation terminology: the use of particular artifacts is mediated by the use of language.

Second, if we apply the Wittgensteinian framework to think about technology, what happens when we use technology can be further conceptualized by using a different kind of vocabulary, which goes beyond mediation and which helps to bring out the social dimension of technology use in a way that has never been done by Ihde. First, we can borrow Wittgenstein's holism to add that these particular uses of technologies are not just about a particular use of artifacts and a particular use of words, or particular "mediations." These uses and mediations (but maybe the term "mediation" is not necessary here) are in turn connected to particular activities, games, and a form of life. For example, using digital social media is not only shaped by material artifacts, but is also embedded within specific social activities and games such as networking, dating, cooking, etc., which each have their own rules. Like any other activity, these so-called "digital" or "technological" engagements are shaped by a wider social-cultural whole and at the same time also help to constitute that whole. Moreover, next to use of the social media platform as a "technology," the same practice also includes uses of language. These uses of language are in turn embedded in the same social-cultural whole. Technology games, as I have called them (Coeckelbergh 2018), are also language games or are at least intimately connected with them. When I use Facebook, I do not only use "technology," "the Internet," material artifacts, and (other) far less visible infrastructures; I also use language. Second, the relation between concrete uses (and, if you wish, mediations) and this whole can be conceptualized in a transcendental way. Whether this should be branded in terms of a transcendental turn (Coeckelbergh 2017, 
180) or whether less emphasis should be put on the term, which sometimes confuses people (including Ihde) because of its proximity to the term "transcendence," the point is the following. Postphenomenology has done a great job in describing how uses of technological artifacts imply mediations of our relations to the world and how it shapes what we do and how we do it. But it has not described precise ways in which these concrete uses and material engagements are in turn shaped by, and co-constitute, the games and forms? of life they are part of. The proposed Wittgensteinian approach enables this.

Take for instance the classic examples of the speedbump and the ultrasound technology. Postphenomenology analyzes this in terms of the mediating role of artifacts, which shape our view of the world and even "act" in the sense that they make us do things. For example, the speedbump shapes what people do (they slow down for the speedbump and because of the speedbump) and Verbeek argues that moral decisions about abortion are mediated and shaped by ultrasound technology (Verbeek 2008). The technologies mediate what people experience and do, for example how the unborn child is perceived by the parents and what drivers do when they see a speedbump. But what is missed here is the transcendental conditions that make possible these constitutions of subjectivity and agency. Before the specific uses and mediations that are described here take place, there is already a language that shapes how we speak about unborn children, there is already a technology and technological context (medical) that shapes our experience, and there is already a traffic game that constrains what we do. While these wholes and games are not totally independent of particular uses (we can try to see things differently by speaking differently, we can use different technologies, we can try to change the game; there is no "thing" called "culture" and we always constitute it again by our uses and performances), they pre-shape and structure what happens in particular cases and uses. Instead of speaking about mediations, then, we can re-describe what happens in transcendental—or what Heidegger would call "ontological"- - terms: both the use of the technology and the use of language are made possible and pre-structured by the grammars that are already there, the games and form of life our activities are linked to. The speedbump is part of a game called "traffic" and if it plays its material "mediating" role at all, it can only do so because it is part of that larger whole. It only makes sense within that larger whole. It receives its power to slow down from humans who delegate that power, and both can play their role and have that power only because they are part of the traffic rules. Instead of saying that the speedbump mediates the behavior of the driver, one could say that the speedbump, together with the traffic rules, the car, the road, and so on, is part of a grammar that shapes and constrains the behavior of the driver. Similarly, the ultrasound itself does not mediate. What is described as mediationthe shaping of the experience of the parents and their decisions - can only happen because there is an entire game and form of life in place that depends on material artifacts but also on language and discourse. Taken together, that grammar makes possible and shapes the experience and choices of the parents, indeed constitutes even their subjectivity. Technology can only "do" things (Verbeek 2005) when it is used and when that use is embedded in particular games and form of life. For example, Verbeek's discussion makes sense within a Dutch context and similar social and cultural contexts (e.g. contexts where there is emphasis on individual decisions, where abortion is legal etc.); in other games (with other rules) and forms of life very different meanings and decisions are taken because there is a different grammar. And Verbeek is right to suggest that without the ultrasound technology things would also look very different, in terms of experience and decisions. But this is not so because the technology has hermeneutic powers on its own, as is suggested by Verbeek's vocabulary of things that "do" things; it is so because the technology, together with a lot of other elements including language, create a grammar which shapes the experience 
and decisions of people. Without a holistic, transcendental and perhaps more structuralist approach, postphenomenology risks to miss the vocabulary to articulate the social embeddedness of technology and the various ways in which not only material artifacts but also rules, discourse, etc. are part of the meaning and use of technology.

Another example is gendered humanoid robots. To explain why a gendered humanoid robot, for example an image of a service robot in the shape of a woman or a female robot in a film like Ex Machina, can be problematic, it is not sufficient to focus on the material artifact itself (fictional or not); it is important to specify how it is used (e.g. as a service robot that does the cleaning or as an AI robot which is created and used by a male protagonist) and how this use and activity is connected with a wider game and form of life in which expectations towards, and treatment of, men and women differs in specific ways, ways which have been criticized by feminists for example. One could say, of course, that these robots "mediate" relations between men and women, but this is very vague and cannot be unpacked only by reference to what the material artifact does. Instead, one needs to articulate (and evaluate) an entire grammar and form of life. Technology, next to discourse for instance, is part of that whole and helps to constitute it. For example, one could argue that the female-shaped robots in films such as Ex Machina help to maintain a specific gender grammar in which women are perceived and treated as objects for men.

Taking seriously the pragmatic dimension of postphenomenology, in particular its emphasis on use, and combining this with a Wittgensteinian outlook (but perhaps a similar approach could be developed on the basis of Heidegger), we thus arrive at a more comprehensive and more interesting postphenomenology and hermeneutics of technology, in which the use of technology is not only a matter of what material artifacts do but is part of a larger whole that includes also language and that shapes concrete uses as much as it is itself constituted by these concrete uses. While it is in principle possible to change the whole - say, change the game-it is not easy to do that; the whole has a kind of normative presence. This is so because it is not just about use or about a particular mediation; it has a grammatical, structural role (Heideggger would say: ontological). It is about the background that gives meaning to our uses of technology and other activities. It is about the whole that we (at least usually) continue to maintain and confirm in our daily activities with technologies. It is about the way we do things-with "we" meaning a particular group, community, society, culture, and so on. Social change is not possible if we do not recognize the normativity and power of this grammar. And a description of the phenomenology and hermeneutics of technology is incomplete if we neglect it.

\section{Language and its Relation(s) to Technology}

The previous discussion also makes us reflect on the relation between language and technology. I propose that there are at least the following ways in which we can define language: as a technology in the sense of a tool, as a medium in the sense of milieu, as a mediator (as postphenomenology uses this word), as a transcendental condition, and as narrative. Let me explain this and explore the implications for thinking about technology, with again a special focus on revising (or moving beyond) postphenomenology.

First, if Wittgenstein could compare language use to use of tools (and if I could turn that metaphor around), then maybe this is possible because language is a technology and words are tools. If we abandon the empirical turn's obsession with material artifacts and learn from 20th-century philosophy of language which shows how words do things (think about 
Austin and Searle), we can construct a definition of tools that includes language and its elements. Paradoxically, the reason why postphenomenology has rejected the study of language is that it simply adopted the postmodern definition of language as a whole of abstract signs. But if we drop that definition and acknowledge the tool-character of language and its elements, we can boldly integrate the study of language into philosophy of technology.

This definition is in line with McLuhan's view of language: language is not a matter of signs but is connected to specific technologies and media (e.g. writing technologies) and is in the end itself a technology, and as such has effects on consciousness. Influenced by Bergson, he writes about 'the extension of man in speech' that enables us to detach ourselves from 'wider reality' instead of remaining involved in the objects of our attention, a 'technical extension of consciousness' (McLuhan 1964, 86). Whether or not we agree with McLuhan's specific claims about the effect of speech, the point is that language, in the form of speech or writing, can thus be analyzed in the same way as we analyze other technology and media.

Second, language can also be seen not so much as a tool but as a medium, in the sense of milieu. Language then appears not as a something we use but more as a kind of environment, an ecology in which we live. This interpretation is congruent with the more "grammatical" and Wittgensteinian approach proposed above, which is not only applicable to technology but also to language. Just as our everyday technologies are part of and contribute to a form of life, language is also interwoven with the larger whole which gives meaning to our lives and which orders and structures our activities and practices.

Third, this leads us to a transcendental interpretation of language. To clarify this, we can make a distinction between language as medium in the sense of mediator (in a postphenomenological sense) and language as transcendental grammar. As I suggested earlier in this paper, language can play the role of mediator in human-world relations and indeed in human-technology relations. As a mediator, language influences how we see the world and shapes our use of technology. However, this makes it seem as if language functions only at what, with Heidegger, we could call the "ontic" level. It is a kind of hermeneutic agent or co-actor. But like technology (or one should say: like other technologies), language also functions at the "ontological" level or what I have called here "grammatical" and transcendental level: language makes possible what we do with technology and in the end even shapes our thinking itself-including thinking about technology. For example, this paper operates and uses language as a tool within the grammar of the English language, which shapes and constrains what is said and what can be said. And when I use the word "robot" there is an entire world connected to this word. Like all technologies, words are not mere tools: they indeed mediate particular relations and, at a deeper or broader level (one which makes possible these mediations), they are part of and co-constitute a semantic order, a grammar that makes sense of particular uses of words and particular uses of things. Language is part of a form of life. For example, when we use robots and talk about them as "machines" or as "companions"- a use of language which matters a lot and mediates our use and interaction with the robot and the societal consequences of that use-this talk and this mediating role of the words and the material artifact are all made possible and structured by a deeper grammar which makes distinctions between living and dead, machines and humans, etc., and which is connected to human-human social relations, e.g. companionship relations. There are companionship games, sex games, industrial games, etc. and our use of robots will be embedded in one or more of these games-each with their own rules. A particular use is hence only possible, and constrained by, these games, which are in turn part of a particular form of life. To realize that there is such a form of life we can imagine alien forms of life, as I did earlier in this paper, but we can also look at other 
cultures. For example, it is well-known that in Japan people think differently about robots, talk differently about robots, treat robots differently, etc. This is so because the grammar and form of life is partly different: modernity mixed with nature religion aspects which for example do not create a wide ontological gap between humans and non-humans. To fully understand particular uses of robots in Japan one needs to make explicit an entire form of life; the same is true for Western uses. Both the use of technology and the use of language are embedded within a deeper grammar, and both technology and language also play a role at that ontological or transcendental level. We do not only use (a particular) language; we also live in (a particular) language. Similarly, we do not only use a particular technology; we also live in a particular technological constellation. And both are part of a form of life. And when Heidegger talked about enframing (Heidegger 1977), I believe he referred to this deeper grammatical order, in this case an order in which modern technology and modern culture are intimately connected and form a background which gives a particular sense to particular activities and uses.

Fourth, what is missing so far in the approach I am sketching is attention to temporality. The notion of narrative is one way to bring in this temporality and at the same time do justice to the social character of our lives with technology. Our lives with technology are not only ruled by, and make sense within, a form of life; they also have a narrative structure. Here other philosophers can offer inspiration: Ricoeur and Gadamer and, going back to ancient times, Aristotle. Both language and technology structure and configure our time. One could say: they mediate the temporality of our existence. Moreover, narratives do not only "mediate" or "configure" but are also part of the form of life, and hence also have the more transcendental role described earlier. For example, narratives about robots (fictional and non-fictional) also shape how we perceive robots, interact with them, and indeed develop and program them. Another way to bring in temporality is to use the notion of performance. I will not further elaborate these ideas here, but some work on performance has already been done in Using Words and Things (2017) and is continued in my new book Moved by Machines (Coeckelbergh 2019), and Wessel Reijers and I proposed a narrative approach to technology based on Ricoeur (e.g. Coeckelbergh and Reijers 2016; Reijers and Coeckelbergh 2020).

To conclude, I have sketched elements for a more Wittgensteinian (and perhaps also: Heideggerian) approach to a phenomenology and hermeneutics of technology, which has involved a move beyond postphenomenology's human-technology relations and focus on the concept of mediation. In particular, the previous operations enabled me to say more about the roles of language and to offer a conceptual framework which renders the phenomenology and hermeneutics of technology more social and more sensitive to the grammatical, transcendental dimension of living with technology. It also enables to integrate the study of language and the study of technology, which thus contributes not to a return to what Mitcham called a "humanities" philosophy of technology as opposed to an "engineering" philosophy of technology, but instead helps to build a better synthesis and hybrid between the two than postphenomenology has managed so far. Whether or not the term "transcendental" is helpful to articulate this synthesis, I believe it is mandatory to at least also consider both technology and language (as technology) in their structuring, grammatical role, and to think further about the ways in which language use and technology use are related.

Note that my extensive use of the term "grammar" relies of course on a metaphor borrowed from (the study and use of) language. In Moved by Machines I will use different kinds of metaphors, borrowed from the performing arts.

To end this paper, I would like to make a note on what the proposed approach implies for thinking about the Anthropocene. 


\section{Anthropocene? Earth and Language as Transcendental Conditions}

Coined by climate scientist Paul Crutzen, the term "Anthropocene" refers to the phenomenon that humans have gained geological agency to such an extent that they are now the most important geological force on the planet, leading to changes in the Earth's atmosphere, climate, and ecosystems. While the term is controversial (for example it has been argued that it is anthropocentric), there has been a small but growing interest in the theme among philosophers of technology. The editors of a special issue of Techné dedicated to the topic (Lemmens, Blok \& Zwier 2017) have argued that philosophers of technology need to take into account the earthly context of technology and technological change and in this way respond critically to the empirical turn:

the Anthropocene as the new terrestrial condition for global humanity calls again for more broad-ranging and whole-oriented approaches in the philosophy of technology, not so much as a correction but as a complement to the now dominant micro-level analyses of concrete artefacts and particular social use contexts favored and promoted by what has been called the 'empirical turn' since the 1990s. Indeed, it urgently requires more macro-oriented and what is more also renewed ontological approaches that question and theorize technology's changing planetary condition (and conditioning). (Lemmens et al. 2017, 123)

I believe the proposed Wittgensteinian (and possibly Heideggerian) approach can contribute to this aim, since it enables a grammatical, transcendental, and indeed ontological outlook, which goes beyond the narrow "micro" focus of empirical turn philosophy of technology.

First, one could say, as Zwier and Blok do in their article for the special issue, that the Anthropocene itself has an ontological status, in the sense that it makes appear the entire planet as a resource to manage (Zwier and Blok 2017, 222). This indeed fits with Heidegger's claim about enframing. The planet becomes a 'standing-reserve' (Heidegger 1977). To use Wittgensteinian language: the Anthropocene constitutes a new form of life, which shapes our thinking and doing. It is not only an "ontic" condition (humans have increased agency and change the planet) but also a kind of transcendental condition. It is not only about what we do or what happens; it is also about how there is something larger that shapes our thinking and our actions. This thus provides the macro perspective asked for by Lemmens et al.

Second, if it is not a good idea to make the entire planet into a standing-reserve and if we therefore reject the Anthropocene and wish to leave this condition (if this is possible at all), one could call for more attention to the earth. And this could once again be framed in ontological or transcendental language. Perhaps the "solution" (but we should move beyond solutionist thinking in order to get out of the Anthropocene) is to recognize the earth itself as a transcendental condition. Form of life is then not only interpreted in a social and cultural way (compare to social and cultural interpretations of Wittgenstein); it is also seen as something that has to do with biology and nature. We humans need the earth in order to live and survive. The earth thus makes possible, functions as a transcendental condition, for all our activities and games, all our uses of technology included. Once we recognize this, we leave the way of thinking that sees the planet as a kind of spaceship which we need to control and manage. And this means we are already leaving the Anthropocene, seen not as a geological or climate condition (ontic) but as a transcendental condition that frames our thinking and doing. 
Recognizing what one could call the terrestrial transcendental can thus show the way out of the Anthropocene.

This direction may well be in line with Stiegler's article (2017) who argues, in a Heideggerian vein, that thinking needs to understand itself as caring, and that we need to take care of our technologies as pharmaka. Caring means already to leave the Anthropocene. It pierces 'the blocked horizon,' to use Stiegler's words (393). But one should add that a thinking that becomes caring should also take care of language (as a technology and pharmakon), and that a thinking that is caring should perhaps in the first place take care of others-human and non-human. The challenge is not only to survive or to 'try to live', as Stiegler puts it (387), if this means living as an individual; the challenge is also to live together. It is about taking care of our technologies but also about taking care of each other. An important transcendental condition for humans is always the social, even if this social is always mixed up with the technological milieus in which we live and the technological tools we use. And the social question can also not be reduced to the question regarding capitalism, even if this is also part of the horizon.

Finally, attention to language as a transcendental condition that shapes this discussion is also helpful here. The controversy about the term "Anthropocene" itself is a good example (Winner (2017) has written on this in the mentioned special issue but I will not further discuss this here). Another example: in spite of the crossovers between humanities and natural sciences that are enabled by the very term "Anthropocene," there is still a tension between the different uses of words: "earth" or "planet" can be seen as geological entities and natural phenomena, but "earth" can also be used in the phenomenological, in particular Heideggerian tradition, as something that is entangled with the lifeworld, that is, with the experience of human beings, or indeed as a transcendental condition. Earth can be an ontic entity or it can be a kind of grammar, a condition of possibility that makes possible our form of life and that perhaps is our form of life. The language we use and the entire game and form of life we assume (e.g. humanities versus natural sciences) is thus crucial for the discussion. If philosophy of technology aims to bring these cultures and forms of life closer together-which I think it should attempt-and if it wants to contribute to thinking about and beyond the Anthropocene, then not only work on material artifacts but also more attention to the role of language, in a Wittgensteinian spirit for example, is much needed. Finding a new language — about technology, about the planet, and about ourselves — can help, in Stiegler's words, 'piercing the blocked horizon' (Stiegler 2017, 393). If we care.

Funding Open Access funding provided by University of Vienna.

Open Access This article is licensed under a Creative Commons Attribution 4.0 International License, which permits use, sharing, adaptation, distribution and reproduction in any medium or format, as long as you give appropriate credit to the original author(s) and the source, provide a link to the Creative Commons licence, and indicate if changes were made. The images or other third party material in this article are included in the article's Creative Commons licence, unless indicated otherwise in a credit line to the material. If material is not included in the article's Creative Commons licence and your intended use is not permitted by statutory regulation or exceeds the permitted use, you will need to obtain permission directly from the copyright holder. To view a copy of this licence, visit http://creativecommons.org/licenses/by/4.0/. 


\section{References}

Achterhuis, H. (Ed.). (2001). American Philosophy of Technology: The Empirical Turn. Bloomington: Indiana University Press.

Coeckelbergh, M. (2015). Language and Technology: Maps, Bridges, and Pathways. New York: AI \& Society.

Coeckelbergh, M. (2017). Using Words and Things: Language and Philosophy of Technology. Abingdon: Routledge.

Coeckelbergh, M. (2018). Technology Games: using Wittgenstein for Understanding and Evaluating Technology. Science and Engineering Ethics, 24, 1503-1519.

Coeckelbergh, M. (2019). Moved by Machines: Performance Metaphors and Philosophy of Technology. New York: Routledge.

Coeckelbergh, M., \& Reijers, W. (2016). Narrative Technologies: A Philosophical Investigation of the Narrative Capacities of Technologies by Using Ricoeur's Narrative Theory. Human Studies, 39, 325-346.

Gier, N. F. (1980). Wittgenstein and forms of life. Philosophy of the Social Science, 10(3), 241-258.

Heidegger, M. (1977). The question concerning technology. In The Question Concerning Technology and Other Essays, trans. W. Lovitt, 3-35. New York: Harper \& Row.

Ihde, D. (1990). Technology and the Lifeworld: From Garden to Earth. Bloomington: Indiana University Press.

Latour, B. (1993). We Have Never Been Modern. Transl. Catherine Porter. Cambridge, MA: Harvard University Press.

Lemmens, P., Blok, V., \& Zwier, J. (2017). Toward a Terrestrial Turn in Philosophy of Technology. Teché Research in Philosophy and Technology, 21(2), 114-126.

McLuhan, M. (1964). Understanding Media: The Extensions of Man (p. 2001). London: Routledge.

Reijers, W., \& Coeckelbergh, M. (2020). Narrative and Technology Ethics. Cham, Switzerland: Palgrave Macmillan.

Serres, M., \& Latour, B. (1995). Conversations on Science, Culture, and Time. Michigan: The University of Michigan Press.

Smith, D. (2015). Rewriting the constitution: A critique of 'postphenomenology'. Philosophy \& Technology, 28, 533-551.

Stiegler, B. (2017). What is Called Caring? Beyond the Anthropocene. Techné Research in Philosophy and Technology, 21(2-3), 386-404.

Tinnell, J. (2015). Grammatization: Bernard Stiegler's Theory of Writing and Technology. Computers and Composition, 37, 132-146.

Verbeek, P.-P. (2005). What Things Do. University Park: The Pennsylvania State University Press.

Verbeek, P.-P. (2008). Obstetric ultrasound and the technological mediation of morality: A postphenomenological analysis. Human Studies, 31(1), 11-26.

Winner, L. (1986). The Whale and the Reactor: A Search for Limits in an Age of High Technology. Chicago: The University of Chicago Press.

Winner, L. (2017). Rebranding the anthropocene: A rectification of names. Techné:Research in Philosophy and Technology, 21(2), 282-294.

Wittgenstein, L. (1953). Philosophische Untersuchungen/Philosophical Investigations, Revised 4th ed. (G.E. M. Anscombe, P. M. S. Hacker \& J. Schulte, Trans.). Malden, MA: Wiley.

Zwier, J., \& Blok, V. (2017). Saving earth: Encountering Heidegger's philosophy of technology in the anthropocene. Techné Research in Philosophy and Technology, 21(2-3), 222-242.

Zwier, J., Blok, V., \& Lemmens, P. (2016). Phenomenology and the empirical turn: A phenomenological analysis of postphenomenology. Philosophy \& Technology, 29(4), 313-333. https://doi.org/10.1007/ s13347-016-0221-7.

Publisher's Note Springer Nature remains neutral with regard to jurisdictional claims in published maps and institutional affiliations. 
Mark Coeckelbergh is Professor of Philosophy of Media and Technology and Vice Dean of the Faculty of Philosophy and Education of the University of Vienna. He is also the former President of the Society for Philosophy and Technology and member of the High-Level Expert Group on AI of the European Commission. He published numerous articles and more than 12 books in the area of philosophy and ethics of technology, including recently AI Ethics (MIT Press), Introduction to Philosophy of Technology (Oxford University Press), and Moved by Machines (Routledge). 